\title{
Research on Employment Management Platform for Multimedia Majors in the Cloud Computing Environment
}

\author{
Xiang Wenxin \\ Sichuan Information Technology College 608040
}

Keywords: multimedia; management platform; kernel density estimation;

\begin{abstract}
In research process of professional employment management platform for multimedia majors in the cloud computing environment, due to the current student employment management algorithm, increasing employment information is unable to meet the requirements of information processing. A design method of such student employment management platform based on improved Chebyshev inequality algorithm in cloud computing environment is proposed. The employment management platform is designed in the cloud computing environment by employing Chebyshev's inequality to estimate probability of student employment change, taking data obtained from student management information system of certain university as sample data set, fusing decision tree algorithm of $\mathrm{k}$ neighbor to find the corresponding property of samples, testing management sample set and classifying input data by the generated decision tree. Simulation experiments show design method of student employment management platform based on improved Chebyshev inequality algorithm in cloud computing environment effectively meets practical needs of student employment.
\end{abstract}

\section{Introduction}

In China, with the continuous improvement of computer technology, comprehensive information management by computer is an important symbol of modern university management and effective measures of work efficiency and management level[1.2.3]. Student employment management is an important part of the administrative work of the University [4.5.6]. However, in construction of student employment management platform in some colleges and universities, mechanism of intercollegiate cooperation, school enterprise cooperation and joint construction is lack and employment management is lagging for multimedia majors, it is difficult to grasp direction of the employment. In this case, the design method of the employment management platform for the students in the environment of cloud computing is the effective way to solve this problem, which has caused the attention of many experts and scholars [7.8.9] .

Due to far-reaching significance in the development of employment management platform for multimedia majors in the cloud computing environment, it has become the focus research of many experts and scholars and has received extensive attention. At the same time, there are a lot of good method are presented [10].

At present, the design methods of the employment management platform are mainly based on ant colony algorithm, particle algorithm and Leapfrog algorithm. Among them, design method of employment management platform in cloud computing environment is commonly based on the particle algorithm. However, with current algorithm for student employment management, it is unable to meet the growing demand for employment information processing.

In order to solve the problems mentioned above, design method based on improved Chebyshev inequality algorithm in cloud computing environment is proposed. Experimental simulation shows that the method can effectively meet the practical needs of multimedia majors.

\section{2 design principles of management platform}

Employment management platform depends on to high-speed campus network, organically combining universities, enterprises and students together, passing the demands information of the 
enterprises, employment guidance, employment dynamics analysis. Specific steps are detailed below.

Under the basis of below equation, student employment management model is established:

$x_{t}+\alpha_{1} x_{t-1}+\alpha_{p} x_{t-p}=\omega_{t}$

where, $\left\{x_{t}\right\}$ is sampling data, $\left\{\alpha_{1}\right\}$ is employment management coefficient.

In design of the students employment management platform, as forecast error of employment management $e_{p n}$ can be derived from

$$
e_{p n}=\sum_{k=0}^{p} a_{k} x_{n-k}
$$

\section{Optimization principle of the management platform}

\subsection{Probability estimation of employment change}

In the optimization process of employment management platform, the probability of student employment changes is estimated by Chebyshev's inequality. Specific steps are as follows:

Provided $X_{1}, X_{2}, \ldots X_{N} \quad(i, j)$ are sampling data in employment characteristic space, $x_{1}, x_{2}, \ldots, x_{n}$ present corresponding observation value of the sample,

At time ${ }^{t}$, probability of characteristic value ${ }^{x_{t}}$ for multimedia major is evaluated with density estimation of kernel function

$p_{r}\left(x_{t}\right)=\frac{1}{N} \sum_{i=1}^{N} K\left(x_{t}-x_{i}\right)$

where, $K$ means kernel function, if Kernel estimation function satisfies normal function $N\left(0, \sigma^{2}\right)$ distribution and $\sigma^{2}$ means the width of Kernel function. Density can be expressed as $P_{r}\left(x_{t}\right)=\frac{1}{N} \sum_{i=1}^{N} \frac{1}{\sqrt{2 \pi \sigma^{2}}} e^{-\frac{1}{2}(x t-x i)}$

\subsection{Implementation of Platform Design}

Taking data of the management information system for multimedia majors in a university as the sample data set, the data set $S$ contains $n$ data samples, marking the data collection as $\left\{c_{1}, c_{2} \ldots, c_{k}\right\}$. Consider $S_{i}$ as the number of data samples in the category $C_{i}$, it is obvious that:

$$
\sum_{i} s_{i}=n
$$

In the process of optimizing the management platform, the expected information of given data objects is classified:

$$
I\left(S_{1}, S_{2}, \ldots S_{K}\right)=-\sum_{i=1}^{K} p_{i} \log _{2}\left(p_{i}\right)
$$

where, $p_{i}$ is the probability of employment management category $C_{i}$.

A decision tree algorithm based on $\mathrm{K}$ nearest neighbor is found to find a property of the corresponding sample set, and the sample set is tested.

If the attribute $\mathrm{A}$ has different $v$ values as $\left\{a_{1}, a_{2}, \ldots a_{v}\right\}$, the $\mathrm{A}$ is divided into $\mathrm{V}$ sub sets $\left\{S_{1}, S_{2}, \ldots S_{v}\right\}$ according to the attribute $\mathrm{S}$. The sample values of the job management data sample are all recorded as $a_{j}$ and probability of $S_{j}\left(a_{j}\right)$ is $n_{j} / n$. As the number of samples $S_{j}$ belonging to the class $C_{i}$ is $S_{i j}$, the conditional probability $S_{i j} / n$ of $C_{i}$ a class is in set $S_{j}$. If 
$\mathrm{A}$ is chosen to test the properties, the entropy of the division of $\mathrm{A}$ is calculated by the following formula:

$E(A)=\sum_{j=1}^{V} \frac{s_{i j}+s_{k j}}{n} I\left(S_{I j} \ldots S_{k j}\right)=\frac{1}{n} \sum_{j=1}^{v} n_{j} I\left(S_{I j} \ldots S_{k j}\right)$

The above equation satisfies $I\left(S_{I j} \ldots S_{k j}\right)=-p_{i j} \log _{2} \sum_{i=1}^{k}$ condition.

Student employment management characteristic A is used to category the sample collection of current branch. Employment management information gain is expressed as follows

$\operatorname{Gain}(A)=I\left(S_{1}, S_{2}, \ldots, S_{K}\right)-E(A)$

The gain rate of employment management information means the information gain adopting with the information entropy split $(A)$.

$\operatorname{split}(A)=-\sum_{I=1}^{V} \frac{\left|S_{i}\right|}{|S|} \log _{2}\left(\frac{\left|S_{i}\right|}{s}\right)$

The information gain rate of the students' employment attribute is defined as

$$
\operatorname{GainRatio}(A)=\frac{\operatorname{Gain}(A)}{\operatorname{Split}(A)}
$$

In optimization process of employment management platform in the cloud computing environment for multimedia majors, maximum attribute A of employment management gain rate GainRatio $(A)$ is chosen as categorical attributes of employment management platform.

\section{Experiments and Simulation}

In order to prove validity of the proposed algorithm in cloud computing environment, based on improved Chebyshev inequality, an experiment is performed. Experimental data source are the real data originated from the student employment management information system of grade 2010 of multimedia specialty in Jilin University. The data contains all the information in three years, which is the data of this specialty students from sophomore year to senior year. Setting data of the first two years as training data and ones of the third years as forecast data, where the total sample size is 9999, the training set size is 6909 and test set size is 3996. Respectively using the improved algorithm, particle algorithm, ant colony algorithm to design employment management platform in cloud computing environment, the accuracy of the experiment is compared, which is to measure the effectiveness of different algorithms, and the results are shown in Table 1.

Table1 Experimental accuracy comparison of different algorithms

\begin{tabular}{lcccc}
\hline Test data set & $\begin{array}{c}\text { Improved algorithm } \\
(\%)\end{array}$ & $\begin{array}{c}\text { Particle } \\
\text { algorithm } \\
(\%)\end{array}$ & $\begin{array}{c}\text { Ant } \\
\text { algorithm } \\
(\%)\end{array}$ & colony \\
\hline A & 98 & 86 & 73 \\
B & 97 & 83 & 71 & \\
C & 97 & 83 & 71 & \\
\hline
\end{tabular}

Table1 represents that, prediction accuracy with improved algorithm of employment management experiments is better than other algorithms. It is because

Improved algorithm in cloud computing environment with Chebyshev's inequality of employment change for multimedia majors was used to estimate the probabilities, so as to ensure the predictive accuracy of the algorithm. 


\section{Conclusions}

In view of the defects in practice process of multimedia specialty student employment management platform, a design method for multimedia specialty student employment management platform based on improved Chebyshev inequality algorithm in cloud computing environment is proposed. The proposed method in this paper is used to make probability estimate of multimedia specialty student employment changes, taking data obtained from student management information system of certain university as sample data set, using decision tree to classify input data, so as to complete the design of multimedia specialty student employment management platform in cloud computing environment. Simulation experiments show design method of student employment management platform based on improved Chebyshev inequality algorithm in cloud computing environment effectively meets practical needs of student employment, playing an enormous acceleration for student employment

\section{References}

[1]Chen Rong. Employment Study of Business Administration Majors [J]. Technology rich Wizard, 2013, (6):25-25.

$[2] \mathrm{Qu}$ Cong. Employment in tourism management students Analysis and Thinking [J]. Modern Women: Theory Edition, 2014, (1):85-85.

[3]Mo Yanfeng,Zhao Xiaoyuan. Analysis the Influence of expertise Hotel Management Majors employment [J]. Exam Week, 2013, (37):159-160.

[4]Wang Li. Analysis the employment Situation of Vocational colleges tourism and hotel management students [J]. Chinese collective economy, 2013, (27):19-19.

[5]Xiao Xiaofeng. Discussion on Improving Management Students' Employment Competition [J]. Era trade, 2014, (3):321-321.

[6]Tu Yanping. Analysis of employment prospects vocational journalism students in the new media environment, [J]. Literature Life:Trimonthly Publication, 2014, (3):256-256.

[7]Zhen Jinhuan,Zhuang Yingying. Analysis of the employment distribution of Public Affairs Management students at Medical Schools [J]. Fujian Medical Journal: Social Sciences, 2014, (1):23-26.

[8]Zou Rong . Reserch on the effect of English teaching hotel management students to promote employment [J]. Education Times, 2013, (12):39-39.

[9]Gao Li. Research on Employment Psychological Adjustment of Higher Hotel Management Majors [J]. Jilin College of Education Ten days, 2013, 29(9):73-74.

[10]Fan Weiwei, Yao Xinyu, Wu Wenbo. Research on Distributed Parallel Simulation Method of Continuous System Model [J]. Computer Simulation, 2014, 31(2):344-348. 